Methodology A retrospective cohort study conducted in the Department of Paediatrics at Monastir included all patients between 1 month and 12 months who underwent UCR after a first episode of UTI between January 2000 and July 2013. Results: 203 infant were included, mean age was 5.69 months (peak was between 3-6 months). Fever was present in 190 infant (93.5\%) of which $32(15.7 \%)$ had prolonged fever. Germs found in culture were dominated by Escherichia coli present in $83 \%$ of children. CRP was positive in $88.6 \%$ of patients. Renal ultrasonography was performed in all cases and showed abnormalities in 57 cases (28\%). The pyelocalicial dilatation was predominant (28 cases). The UCR showed abnormalities in 24 children which utrasonography findings were also abnormal. The most common abnormalities were primary vesico-ureteral reflux; 14 infants $(6.9 \%)$ had high grade (bilateral in 7 cases). 6 patients (3\%) had unilateral had low grade reflux in 3 cases and bilateral in 3 cases.

Conclusion As recommended, the indications of UCR in infants should be limited to abnormal ultrasound or recurrent UTI.

\section{PO-0784 NEUROLOGICAL COMPLICATIONS IN TWIN PREGNANCIES WITH FETAL DEATH}

${ }^{1} \mathrm{~A}$ Ben Thabet, ${ }^{1} \mathrm{~N}$ Hentati, ${ }^{1} \mathrm{Y}$ Belfitouri, ${ }^{2} \mathrm{H}$ Fourati, ${ }^{1} \mathrm{R}$ Regaieg, ${ }^{1} \mathrm{~L}$ Walha, ${ }^{2} \mathrm{Z}$ Mnif, ${ }^{1}$ A Bouraoui, ${ }^{1}$ A Gargouri. 'Neonatology, CHU Hédi Chaker Sfax Tunisia, Sfax, Tunisia; ${ }^{2}$ Radiology, CHU Hédi Chaker Sfax Tunisia, Sfax, Tunisia

\subsection{6/archdischild-2014-307384.1420}

Introduction A monofœtal death is described in 0.5 to $7 \%$ of twin pregnancies. The neurological complications risk in the surviving twin is estimated at $18 \%$ in monochorionic pregnancies and it is based on vascular anastomoses between the fetal circulations.

Purpose To insist in twin pregnancy monitoring in case of one foetal death to avoid cerebral damage in the surviving twin.

Materials and Methods We report observations of 5 hospitalised newborns in Sfax Neonatology Department from August 2003 to October 2007 who presented neurological complications following foetal death of their twins.

Results The pregnancy was dichorionic in one case, monochorionic in the others. A twin transfusion syndrome was diagnosed in one case. The average term was 36 weeks and twin fetal death occurred at an average term of 33 weeks. The delivery was vaginal in two cases and caesarean in three. One child was clinically asymptomatic and the others showed neurological distress : convulsions or hypotonia. Transfontanellar ultrasound was done in one case, tomography in two cases, MRI in one case and Angio MRI in one case. Brain lesions were ischaemic in four cases and haemorrhagic in one. Death occurred in one case at the age of 10 days. There was a psychomotor retardation in the others with epilepsy in two cases.

Conclusion Cerebral damage in the surviving twin is based on different pathophysiological mechanisms. Strict monitoring should guide our choice of the appropriate moment of delivery.

\section{PO-0785 RELATIONSHIP BETWEEN HEART RATE AND BLOOD PRESSURE IN PAEDIATRIC PATIENTS REFERRED FOR AMBULATORY BLOOD PRESSURE MONITORING (ABPM)}

M Congdon, G Kainer, S Kennedy. Nephrology, Sydney Children's Hospital and UNSW, Sydney, Australia

10.1136/archdischild-2014-307384.1421
Objective To establish the relationship between heart rate (HR), systolic blood pressure (SBP), diastolic blood pressure DBP, pulse pressure (PP), and mean arterial pressure (MAP) in paediatric patients from ambulatory blood pressure monitoring (ABPM) records.

Design and methods 100 ABPM studies from 75 children; mean age 12.1 years who underwent $24 \mathrm{~h} \mathrm{BP}$ monitoring in our paediatric nephrology clinic were analysed. We acquired demographic data and readings of $\mathrm{HR}, \mathrm{SBP}$ and DBP, PP and MAP from the ABPM records. The relationship between these variables was examined using regression statistical analysis. None of the children were on drugs known to affect heart rate or blood pressure.

Results Highly significant correlation coefficients were found between increasing HR and SBP, DBP and MAP: 0.40 (95\% confidence intervals $0.38-0.43), 0.39(0.36-0.41)$ and $0.37(0.35-$ 0.39 ), all $\mathrm{p}<0.001$ respectively. Boys had a lower mean clinic HR than girls 84 vs $91 \mathrm{bpm} \mathrm{p}<0.02$. However, there was no difference in the response to increasing $\mathrm{HR}$ and BP parameters between the genders. HR and BP parameters correlated more strongly during awake periods than during sleep.

Conclusions In this pilot study, we found that as HR increases above basal, Blood Pressure increases in a predictable fashion. There are differences in the response of BP to increasing HR during asleep and awake periods. This pilot study confirms that we may be able to 'adjust' BP readings for tachycardia to improve our interpretation of ABPM.

\section{PO-0786 PRENATAL DIAGNOSIS OF GLOMERULOCYSTIC KIDNEY DISEASE DUE TO MUTATION HNF 1B. IMPORTANCE OF GENETIC TEST}

${ }^{1} \mathrm{JC}$ Len Aguilera, ${ }^{1} \mathrm{C}$ Salado Marín, ${ }^{1} \mathrm{Jl}$ Montiano Jorge, ${ }^{2} \mathrm{G}$ Perez de Nanclares Leal. ${ }^{1}$ Pediatrics, HUA Txagorritxu, Vitoria-Gasteiz, Spain; ${ }^{2}$ Genetics, HUA Txagorritxu, VitoriaGasteiz, Spain

\subsection{6/archdischild-2014-307384.1422}

Background HNF 1B is a key factor for the normal development of the kidney and pancreas transcription. Mutations affecting the gene encoding this factor are related to different phenotypes of renal disease among glomerulocystic kidney disease (GCKD) is included.

GCKD is entity characterised by glomerular cysts with dilatation of the Bowman space and adjacent tubules.

Methods Case report: Male patient, 7 years old, with renal cystic disease prenatal diagnosis of bilateral cortical cysts distribution. Unrelated parents, mother with IgA nephropathy, no alterations of hepatic metabolism or glucose. At birth, had very enlarged kidneys with increased echogenicity and loss of cortico medullary differentiation without other extrarenal findings. The disease has slowly evolved, with increased number of cysts, always cortical distribution. No impairment of renal function, normal BP. Genetic study was performed.

Results Heterozygous mutation HNF 1B was identified (c. 1¿_1674+del), consisting of the deletion in one of its complete gene alleles. Neither parent is a carrier of the mutation.

Conclusions The demonstration of de novo gene mutation in this patient confirms the aetiology of cystic disease.

The test is very useful because it allows early diagnosis, noninvasive, allows estimating a prognosis and genetic counselling to the family. 